coloboma, cataract, and nystagmus. Mental retardation required special school placement for 16, and only 3 attended normal schools without extra assistance. The finding of ocular abnormalities in a child suspected of having FAS should strengthen the diagnosis.

Developmental neurotoxicity of PCBs in humans is reviewed from the Institute of Environmental studies, University of Illinois at UrbanaChampaign, Urbana, IL. (Schantz SL. Neurotoxicol and Teratology May/June 1996;18:217-227). Studies included those in Yusho, Japan; Yucheng, Taiwan; Michigan; North Carolina; Oswego, NY; New Bedford, MA; on Inuit people in the Arctic regions of Quebec; and in Faroe Islanders. Concurrent methylmercury poisoning may be an issue in interpretation of some studies. Children born to mothers exposed to PCBs showed abnormalities in behavior and development, including higher activity levels, behavior problems, lower IQ scores, decreased birth weight and head circumference, lowered scores on the Brazelton Neonatal Battery, deficits in memory at 4 years, and delays in psychomotor development. Although the deficits in cognition were often small, the public health implications of low-level PCB exposure was compared to that of lead exposure. At a population level, a decrease of 4 points on the Bayley Scales is estimated to result in a $50 \%$ increase in the number of children with subnormal scores. Subtle alterations in neuropsychological functioning caused by exposure to these environmental toxins were proposed as explanations for some cases of ADHD, either by a direct effect on the brain in the prenatal period or secondary to effects on thyroid function. The potential impact of postnatal exposure to PCBs via breast milk was also reviewed.

Maternal smoking is a preventable cause of mental retardation according to a study at the Rollins School of Public Health of Emory University, Atlanta, GA. (Drews CD et al. Pediatrics April 1996;97:547553). Children whose mothers smoked one pack a day during pregnancy had more than a $75 \%$ increase in mental retardation. Maternal smoking has also been linked to lesser impairments of cognitive function and academic achievement, auditory deficits, and behavioral problems in children.

Environmental factors should be considered more frequently as potential causes of attention deficits and learning disabilities.

\title{
CNS IRRADIATION EFFECTS ON PUBERTY AND GROWTH
}

The relation between age at irradiation, sex, and age at puberty onset was determined in 36 children treated with high-dose irradiation for tumors anatomically distant from the hypothalamic-pituitary region at the New York University Medical Center, St Luke's/Roosevelt Hospital, and Memorial Sloan Kettering Cancer Center, New York. Twenty six also received chemotherapy. Age at onset of puberty and pubarche was significantly earlier in girls but not in boys. The mean age at onset of puberty in both boys and girls was linearly correlated with age at diagnosis and irradiation, and was inversely related to body weight. (Oberfield SE et al. Age at onset of puberty following high-dose central nervous system radiation therapy. Arch Pediatr Adolesc Med June 1996;150:589-592). (Reprints: Sharon E Oberfield MD, New York University Medical Center, 550 First Ave, New York, NY 10016).

COMMENT. High dose cranial irradiation may cause precocious puberty in girls, particularly in those who are overweight. 
High-dose methotrexate for acute lymphocytic leukemia in young children did not cause neurological abnormalities or MRI changes in a study of 12 children treated at the University Hospital of Tronheim, Norway. (Seidel $\mathrm{H}$ et al. Acta Paediatr April 1996;85:450-3). Some previous studies have demonstrated reversible acute and subacute neurotoxicity following methotrexate (MTX) therapy for ALL. The possible role of folinic acid rescue in avoiding MTX toxicity needs further study.

\section{ANTICONVULSANT DRUG TOXICITY}

\section{VALPROATE INDUCED OBESITY AND POLYCYSTIC OVARIES}

Fourteen $(64 \%)$ of 22 women receiving valproate monotherapy for epilepsy had polycystic ovaries, hyperandrogenism, or both, in a study at the Departments of Neurology, Obstetrics and Gynecology, and Pediatrics, University of Oulu, Finland. They had a progressive obesity associated with hyperinsulinemia and low serum insulin-like growth factor-binding protein 1 , leading to hyperandrogenism and polycystic ovaries. The mean duration of treatment was 7 years, and the mean daily dose of valproate was $1070 \mathrm{mg}$. In contrast, polycystic ovaries/hyperandrogenism occurred in 9 (21\%) of 43 women receiving carbamazepine monotherapy and $8(19 \%)$ of 43 in a control group. (Isojarvi JIT et al. Obesity and endocrine disorders in women taking valproate for epilepsy. Ann Neurol May 1996;39:579-584). (Respond: Dr Isojarvi, Department of Neurology, University of Oulu, FIN-90220 Oulu, Finland).

COMMENT. Polycystic ovarian syndrome (PCOS), hyperandrogenic chronic anovulation, is characterized clinically by hirsutism and menstrual disorders. Obesity occurs in 30 to $50 \%$ of patients affected. It may have multiple etiologies, including genetic, endocrine, metabolic, and neurologic. PCOS induced by valproate medication for epilepsy has been attributed to the coincidental obesity and resultant endocrine abnormalities. An increased incidence of PCOS among untreated epileptic women is greater with left than with right-sided temporal lobe foci. Antiseizure medications other than valproate induce hepatic enzymes that reduce testosterone levels and tend to moderate hyperandogenism. Hertzog AG, at the Harvard Neuroendocrine Unit, Beth Israel Hospital, Boston, MA, suggests that valproate may not be the primary cause of PCOS, citing epileptic and neurologic factors (Ann Neurol May 1996;39:559-560).

\section{CARNITINE IN VALPROATE-INDUCED HYPERAMMONEMIA}

The effect of carnitine supplementation in valproic acid (VPA) treated patients presenting with hyperammonemia was investigated in 69 children and young adults seen at the Zentrum der Kinderheilkunde, GoetheUniversitat Frankfurt, and Universitat Erlanger, FRG. Plasma total carnitine was low ( $27 \mathrm{mcmol} / 1 \mathrm{cf}$ normal of $40 \mathrm{mcmol} / 1)$ in 48 tested. After supplements of carnitine ( $1 \mathrm{gm} / \mathrm{m} 2$ per day) in 15 patients, the plasma ammonia decreased by $25 \%$ after 9 days and $46 \%$ after 80 days. The plasma free carnitine was increased by $12 \%$. Plasma ammonia concentrations were significantly correlated with free plasma carnitine \%. (Bohles H, Sewell AC, Wenzel D. The effect of carnitine supplementation in valproate-induced hyperammonaemia. Acta Paediatr April 1996;85:446-9). (Respond: Dr H Bohles, Zentrum der Kinderheilkunde, Theodor Stern Kai 7, 60590 Frankfurt/Main, FRG). 